\title{
Hydrocortisone suspension formulations are not necessarily the same in the treatment of children with congenital adrenal hyperplasia
}

\author{
Kyriakie Sarafoglou ${ }^{1,2}$, Mutaz M Jaber ${ }^{1}$, Mahmoud Al-Kofahi' ${ }^{1}$ and Richard C Brundage ${ }^{1}$ \\ ${ }^{1}$ Department of Experimental and Clinical Pharmacology, University of Minnesota, Minneapolis, Minnesota, USA and \\ 2Department of Pediatrics, University of Minnesota Masonic Children's Hospital, Minneapolis, Minnesota, USA
}

\author{
Correspondence \\ should be addressed \\ to K Sarafoglou \\ Email \\ saraf010@umn.edu
}

\section{Dear Editor,}

We wish to congratulate the authors of the paper entitled 'Paediatric population pharmacokinetic modelling to assess hydrocortisone replacement dosing regimens in young children' (1) in which a sophisticated modeling approach was applied to cortisol concentrations in children with congenital adrenal hyperplasia (CAH). It nicely demonstrates how information from other studies and other populations can inform sparsely sampled data in pediatrics. There was, however, a statement that requires additional commentary as it perpetuates a myth regarding hydrocortisone therapy in children with CAH.

The authors state that hydrocortisone suspensions 'have been shown not to be bioequivalent to the hydrocortisone tablet' and base this statement on an article from 2001 by Merke et al. (2). The article reported that patients who used a commercially available hydrocortisone cypionate suspension required higher daily hydrocortisone doses, had higher 17-hydroxyprogesterone and androstenedione levels and increased weight gain and hypertension compared to the tablets. Because of the report, hydrocortisone cypionate suspension was taken off the market. However, Merke et al. indicated their study results were specific only to the bioavailability of hydrocortisone cypionate, and not to all hydrocortisone suspension formulations. Indeed, the authors clarify with the statement that 'The stability and dosage uniformity of hydrocortisone suspensions prepared from tablets and powder were found to provide a uniform dose' (2) and support their statement with a reference by Fawcett et al. (3).
Since 2001, other studies have also shown that extemporaneously compounded alcohol-free hydrocortisone suspensions based on published methods have excellent stability $(4,5,6,7,8)$. Moreover, a 6-hour serial sampling cortisol pharmacokinetic and pharmacodynamic response study in children with $\mathrm{CAH}(9)$ found using a dose- and BSA-normalized area-under-thecurve analysis that the absorption of an extemporaneously compounded alcohol-free hydrocortisone suspension $(8,10)$ was not different compared with commercial hydrocortisone tablets (9). In addition, the study found that adrenal steroid concentrations, mean weight and height z-scores were also comparable between children on tablets and suspension. However, this is not to say that hydrocortisone suspensions are the answer. Extemporaneously compounded drugs are not subject to the same quality control measures as commercial medications licensed by the FDA, which can lead to inconsistent quality among different compounding pharmacies and varied results in patients $(11,12,13)$. All of the above highlights the critical need for a commercially available pediatric hydrocortisone formulation that allows for dosage units less than $2.5 \mathrm{mg}$ in young children with $\mathrm{CAH}$. The lowest dose currently available in the US is a scored $5 \mathrm{mg}$ tablet.

As a final thought, the authors' focus on establishing a population pharmacokinetic model of cortisol for the purpose of assessing the ability of various hydrocortisone regimens to keep cortisol concentrations in a physiological range. However, the focus on keeping cortisol concentrations in a range similar to healthy children ignores more relevant 17-hydroxyprogesterone and

Published by Bioscientifica Ltd. 
androstenedione biomarker information and variability in the sensitivity of the hypothalamic-pituitary-adrenal axis to cortisol. In fact, measurements of cortisol concentrations are not part of standard care nor included in the recommend monitoring guidelines of the Endocrine Society CAH consensus (14). There is simply too much between-subject variability in the pharmacodynamic response to cortisol $(15,16,17)$. We know that standard dosing guidelines of $10-15 \mathrm{mg} / \mathrm{m}^{2} /$ day will result in some children being over-suppressed, while others will still have elevated androgens. What is critically needed in the field is defining the hydrocortisone dose - exposure long-term outcome relationships. Accepting comparative normalization of biomarkers to healthy children as the gold standard is not sufficient to address the long-term health deficits observed in affected individuals with $\mathrm{CAH}$ that extend into adulthood.

\section{Declaration of interest}

$\mathrm{K} S$ receives research support from Office of Orphan Products Development of the Food and Drug Administration (R01FDR0006100), National Institutes of Health National Cancer Institute (5R01CA181024), Spruce Biosciences, Alexion and Neurocrine Biosciences and serves on the scientific advisory board for Eton Pharmaceuticals but does not accept personal income for these activities. R C B receives research support from Office of Orphan Products Development of the Food and Drug Administration (R01FDR0006100) and serves on the scientific advisory board for Eton Pharmaceuticals but does not accept personal income for these activities. The rest of the authors have no financial disclosures to report.

\section{Funding}

This research did not receive any specific grant from any funding agency in the public, commercial or not-for-profit sector.

\section{References}

1 Michelet R, Melin J, Parra-Guillen ZP, Neumann U, Whitaker JM, Stachanow V, Huisinga W, Porter J, Blankenstein O, Ross RJ et al. Paediatric population pharmacokinetic modelling to assess hydrocortisone replacement dosing regimens in young children. European Journal of Endocrinology 2020183 357-368. (https://doi. org/10.1530/EJE-20-0231)

2 Merke DP, Cho D, Calis KA, Keil MF \& Chrousos GP. Hydrocortisone suspension and hydrocortisone tablets are not bioequivalent in the treatment of children with congenital adrenal hyperplasia. Journal of Clinical Endocrinology and Metabolism 200186 441-445. (https://doi. org/10.1210/jcem.86.1.7275)

3 Fawcett JP, Boulton DW, Jiang R \& Woods DJ. Stability of hydrocortisone oral suspensions prepared from tablets and powder. Annals of Pharmacotherapy 199529 987-990. (https://doi. org/10.1177/106002809502901005)
4 Santovena A, Llabre's M \& Farina JB. Quality control and physical and chemical stability of hydrocortisone oral suspension: an Interlaboratory Study. International Journal of Pharmaceutical Compounding 201014 430-435.

5 Manchanda A, Laracy M, Savji T \& Bogner RH. Stability of an alcohol-free, dye-free hydrocortisone $(2 \mathrm{mg} / \mathrm{mL}$ ) compounded oral suspension. International Journal of Pharmaceutical Compounding 2018 22 66-75.

6 Orlu-Gul M, Fisco G, Parmar D, Gill H \& Tuleu C. A new reconstitutable oral paediatric hydrocortisone solution containing hydroxypropylbeta-cyclodextrin. Drug Development and Industrial Pharmacy 201339 1028-1036. (https://doi.org/10.3109/03639045.2012.696654)

7 Gupta VD. Chemical stability of hydrocortisone in humco simple syrup and ora-sweet vehicles. International Journal of Pharmaceutical Compounding 201014 76-77.

8 Chong G, Decarie D \& Ensom JHH. Stability of hydrocortisone in extemporaneously compounded suspension. Journal of Clinical Pharmacology 200313 100-110.

9 Sarafoglou K, Gonzalez-Bolanos MT, Zimmerman CL, Boonstra T, Yaw Addo O \& Brundage R. Comparison of cortisol exposures and pharmacodynamic adrenal steroid responses to hydrocortisone suspension vs. commercial tablets. Journal of Clinical Pharmacology 201555 452-457. (https://doi.org/10.1002/jcph.424)

10 Allen LV. Formulations: hydrocortisone $2 \mathrm{mg} / \mathrm{mL}$ oral liquid. International Journal of Pharmaceutical Compounding 2004856.

11 Gudeman J, Jozwiakowski M, Chollet J \& Randell M. Potential risks of pharmacy compounding. Drugs in R\&D 201313 1-8. (https://doi. org/10.1007/s40268-013-0005-9)

12 Al-Rayess H, Fleissner K, Jaber M, Brundage RC \& Sarafoglou K. Manipulation of hydrocortisone tablets leads to iatrogenic Cushing syndrome in a 6-year-old girl with CAH. Journal of the Endocrine Society 20204 bvaa091. (https://doi.org/10.1210/jendso/bvaa091)

13 Barillas JE, Eichner D, Van Wagoner R \& Speiser PW. Iatrogenic Cushing syndrome in a child with congenital adrenal hyperplasia: erroneous compounding of hydrocortisone. Journal of Clinical Endocrinology and Metabolism 2018103 7-11. (https://doi. org/10.1210/jc.2017-01595)

14 Speiser PW, Arlt W, Auchus RJ, Baskin LS, Conway GS, Merke DP, Meyer-Bahlburg HFL, Miller WL, Murad MH, Oberfield SE et al. Congenital adrenal hyperplasia due to steroid 21-hydroxylase deficiency: an Endocrine Society clinical practice guideline. Journal of Clinical Endocrinology and Metabolism 2018103 4043-4088. (https:// doi.org/10.1210/jc.2018-01865)

15 Melin J, Parra-Guillen ZP, Michelet R, Truong T, Huisinga W, Hartung N, Hindmarsh P \& Kloft C. Pharmacokinetic/ pharmacodynamic evaluation of hydrocortisone therapy in pediatric patients with congenital adrenal hyperplasia. Journal of Clinical Endocrinology and Metabolism 2020105 dgaa071. (https://doi. org/10.1210/clinem/dgaa071)

16 Al-Kofahi M, Ahmed MA, Jaber MM, Tran TN, Willis BA, Zimmerman CL, Gonzalez-Bolanos MT, Brundage RC \& Sarafoglou K. An integrated PK-PD model for cortisol and the 17-hydroxyprogesterone and androstenedione biomarkers in children with congenital adrenal hyperplasia. British Journal of Clinical Pharmacology 2020 In press. (https://doi.org/10.1111/bcp.14470)

17 Sarafoglou K, Zimmerman CL, Gonzalez-Bolanos MT, Willis BA \& Brundage R. Interrelationships among cortisol, 17-hydroxyprogesterone, and androstenendione exposures in the management of children with congenital adrenal hyperplasia. Journal of Investigative Medicine 201563 35-41. (https://doi.org/10.1097/ JIM.0000000000000121) 